\title{
WORK ENVIRONMENT CHANGES AND STRESS. THE ROLE OF WORK TO FAMILY CONFLICT
}

Fabrice De Zanet*, Ph.D. Student, Florence Stinglhamber, Ph.D., Christian Vandenberghe, Ph.D., Catholic University of Louvain, Ilse Cornelis, Ph.D. Student, Ghent University, William D'hoore, M.D., Catholic University of Louvain, Véronique De Keyser, Ph.D., Isabelle Hansez, Ph.D., University of Liège, Roger Tjeka, M.D., Catholic University of Louvain and Peter Vlerick, Ph.D., Ghent University

First, many studies have shown the negative impact of organizational change on survivors. These negative consequences range from psychosocial strains to decreased performance. Second, because organizational change is often associated with downsizing, it is reasonable to think that such a reduction of the workforce modifies working conditions. Actually, it has been shown that organizational change contributes to the intensification of work, both quantitatively and qualitatively, and that these two forms of intensification are related to stress. Third, empirical data indicate that work to family conflict, defined by Greenhaus and Beutell (1985, p. 77) as "a form of interrole conflict in which role pressures from the work and family domains are mutually incompatible in some respect", has a negative impact on wellbeing.

Our objective was to investigate relations between intermediate factors that would help us to better understand how well-being could be impaired in a context of organizational change. Our theoretical model hypothesized a double mediation between organizational change and stress through work intensification and work to family conflict. First, we hypothesized that the number of work environment changes employees have been confronted with would increase workload both quantitatively and qualitatively. Second, we assumed this intensification to be positively related to work to family conflict. Third, we hypothesized that stress would raise as work to family conflict increases.

Our results confirmed that organizational change may have a negative impact on stress. As hypothesized, the number of changes increased work stress through quantitative intensification and work to family conflict. Surprisingly, qualitative intensification was not related to work environment changes. However, this form of work intensification appeared to have a more complex impact: qualitative intensification had a significant and positive impact on quantitative intensification as well as a significant and negative impact on stress.

CORRESPONDING AUTHOR: Fabrice De Zanet, Faculty of Psychology (PSP), Department of Social and Organizational Psychology, Place Cardinal Mercier, 10, 1348 Louvain-la-Neuve, BELGIUM. fabrice.dezanet@psp.ucl.ac.be 